This article was downloaded by: [EBSCOHost EJS Content Distribution]

On: 23 October 2009

Access details: Access Details: [subscription number 911724993]

Publisher Taylor \& Francis

Informa Ltd Registered in England and Wales Registered Number: 1072954 Registered office: Mortimer House, 37-41 Mortimer Street, London W1T 3JH, UK

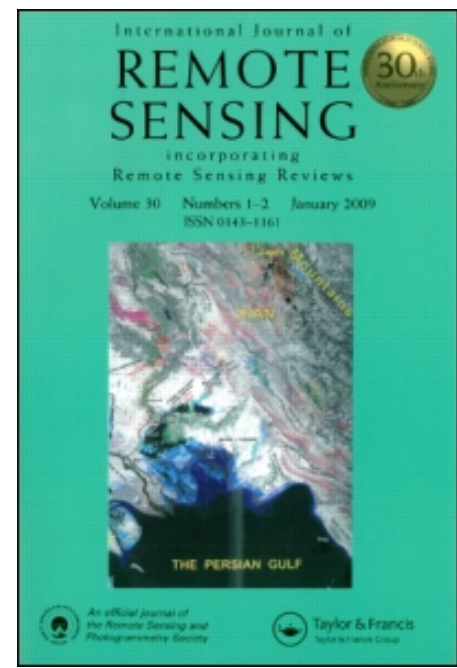

International Journal of Remote Sensing

Publication details, including instructions for authors and subscription information:

http://www.informaworld.com/smpp/title content=t713722504

\title{
Sieving nonlinear internal waves through path prediction
}

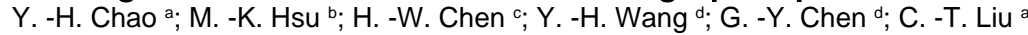

${ }^{a}$ Institute of Oceanography, National Taiwan University, Taipei, Taiwan, Republic of China ${ }^{\mathrm{b}}$ Northern Taiwan Institute of Science and Technology, Taipei, Taiwan, Republic of China ${ }^{\circ}$ Department of Maritime Police,

Central Police University, Taoyuan, Taiwan, Republic of China ${ }^{d}$ Institute of Physical Oceanography, National Sun Yat-sen University, Kaohsiung, Taiwan, Republic of China

Online Publication Date: 01 November 2008

To cite this Article Chao, Y. -H., Hsu, M. -K., Chen, H. -W., Wang, Y. -H., Chen, G. -Y. and Liu, C. -T.(2008)'Sieving nonlinear internal waves through path prediction', International Journal of Remote Sensing,29:21,6391 - 6402

To link to this Article: DOI: $10.1080 / 01431160802175413$

URL: http://dx.doi.org/10.1080/01431160802175413

\section{PLEASE SCROLL DOWN FOR ARTICLE}

Full terms and conditions of use: http://www.informaworld.com/terms-and-conditions-of-access.pdf

This article may be used for research, teaching and private study purposes. Any substantial or systematic reproduction, re-distribution, re-selling, loan or sub-licensing, systematic supply or distribution in any form to anyone is expressly forbidden.

The publisher does not give any warranty express or implied or make any representation that the contents will be complete or accurate or up to date. The accuracy of any instructions, formulae and drug doses should be independently verified with primary sources. The publisher shall not be liable for any loss, actions, claims, proceedings, demand or costs or damages whatsoever or howsoever caused arising directly or indirectly in connection with or arising out of the use of this material. 


\title{
Sieving nonlinear internal waves through path prediction
}

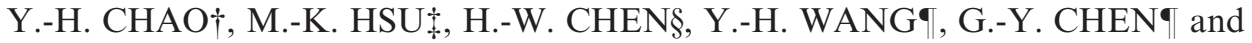 \\ C.-T. LIU*† \\ $\dagger$ Institute of Oceanography, National Taiwan University, Taipei, Taiwan, \\ Republic of China \\ $\$$ Northern Taiwan Institute of Science and Technology, Taipei, Taiwan, \\ Republic of China \\ $\S$ Department of Maritime Police, Central Police University, Taoyuan, Taiwan, \\ Republic of China \\ -Institute of Physical Oceanography, National Sun Yat-sen University, Kaohsiung, \\ Taiwan, Republic of China
}

(Received 30 April 2007; in final form 28 March 2008)

\begin{abstract}
Nonlinear internal waves (NLIWs) have been studied as unusual phenomena in the ocean for several decades. As the quality, quantity and variety of satellite images have increased, NLIWs have been found as a ubiquitous phenomenon over the continental shelf. In the northern South China Sea (SCS), satellite images from both optical and microwave sensors show that there are trains of NLIW packets near Dongsha Atoll $\left(20.7^{\circ} \mathrm{N}, 116.8^{\circ} \mathrm{E}\right)$. Each packet contains several NLIW fronts. These NLIW packets are nearly parallel to each other and they are refracted, reflected or diffracted by changes in ocean-bottom topography. NLIW propagation speed depends on the stratification of water density and the water depth, and less on the wave amplitude. As NLIWs propagate westwards from the northern SCS at about $3000 \mathrm{~m}$ depth, up onto the shelf near Dongsha Atoll, their propagation speed falls with water depth from $2.9 \mathrm{~m} \mathrm{~s}^{-1}$ to $1 \mathrm{~m} \mathrm{~s}^{-1}$ or less. This causes difficulty in relating the NLIW packets in various satellite images. Based on archived hydrographical data, the Kortewegde Vries $(\mathrm{KdV})$ theory of weakly propagating NLIWs and the assumption that the bright/dark lines in the satellite images are centres of convergence/divergence of NLIW fronts, the path and the propagation speed of NLIWs can be predicted with $-1 \%$ in bias and $4.4 \%$ in standard deviation. With this accuracy, we can (1) sort the NLIW packets in the same satellite image into different groups of NLIWs (in each group, NLIWs were generated at the same place but at successive tidal cycles); (2) relate NLIW packets in consecutive satellite images obtained 1 day apart; and (3) confirm or search for faint signals of NLIW fronts in a satellite image.
\end{abstract}

\section{Introduction}

From visible-light satellite images (Fett and Rabe 1977, Bole et al. 1994), synthetic aperture radar (SAR) (Liu et al. 1998, Hsu et al. 2000, Liu and Hsu, 2004, Liu et al. 2004, Zhao et al. 2004) and MODerate-resolution Imaging Spectroradiometer (MODIS) images (Liu et al. 2006), nonlinear internal waves (NLIWs) can be found

\footnotetext{
*Corresponding author. Email: ctliu@ntu.edu.tw
} 


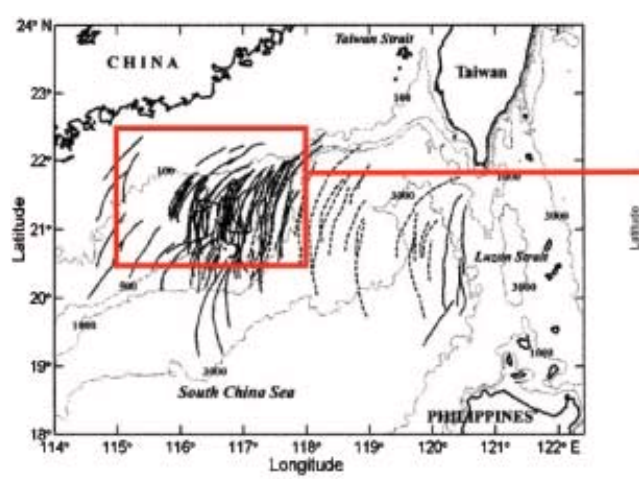

(a)

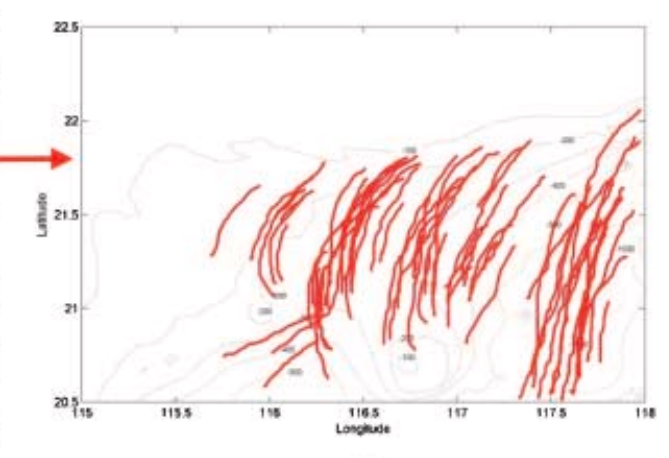

(b)

Figure 1. (a) Bathymetry and internal wave distribution map in the South China Sea. Each solid line represents a multiple-wave NLIW packet. Each dashed line represents a single-wave NLIW (Zhao et al. 2004). (b) The red lines are locations of the NLIW fronts as observed in MODIS images of April and May, during 2002-2005.

over most continental shelves, including that of the South China Sea (SCS). Zhao et al. (2004) collected hundreds of European Remote Sensing satellite (ERS)-1, ERS-2 and Radarsat SAR images, and SPOT images, to plot the distribution of NLIWs in the SCS (figure 1(a)). Figure 1(b) shows the location of the NLIW fronts in MODIS images.

In regions of rough bathymetry, such as the continental shelf of the northern SCS, NLIWs will be refracted, reflected or diffracted by various topographic features. In one satellite image, there may be many packets of NLIW fronts (figure 2). It is not clear which fronts belong to the same packet, and which packets came from the same source region, that is were generated at the same place but at different tidal cycles. If there are continuous images from satellites, the location of each NLIW packet can be tracked at a different time, and the NLIW packets categorized according to their source region, generation mechanism, and phase in relation to the

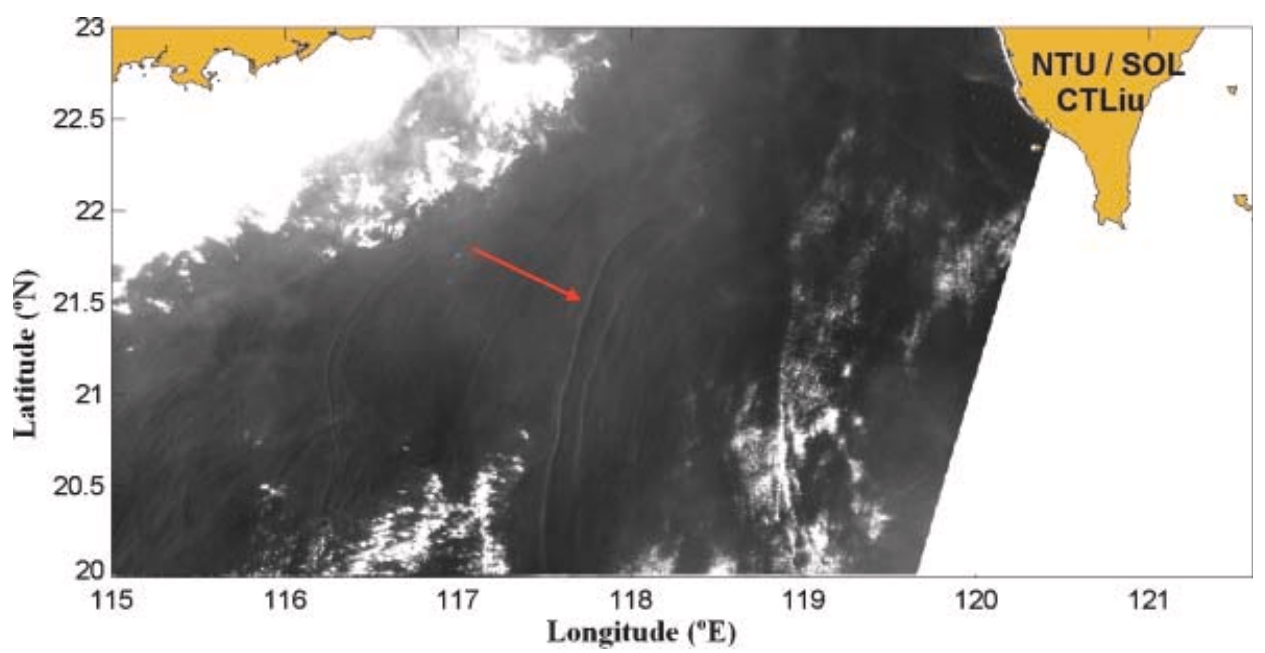

Figure 2. Terra MODIS image of 7 May 2003. The major NLIW front in a packet of two fronts is marked with a red arrow. There are several NLIW packets west (ahead) of this front. It is not clear which ones are related to this major NLIW front. 
tidal current. In most cases, the time lapse between two satellite images is too long, such that the location of an NLIW front in the new image cannot be identified easily.

The relationships between NLIWs in the SCS were studied by in situ observation by Ramp et al. (2004), who categorized the NLIWs into two types: A-waves of larger amplitude with periods of $24 \mathrm{~h}$; and B-waves of smaller amplitude with periods of $24.8 \mathrm{~h}$. In satellite images, frontal patterns of higher contrast and more numerous fronts within a packet are assumed to be A-waves, with packets separated by $24 \mathrm{~h}$, while B-waves have relatively less contrast and a smaller number of fronts within a packet. These assumptions are used in the analysis described in this work.

Under the condition of non-continuous satellite images, the propagation velocity of an NLIW must be known before predicting its path as a function of time and sieving out the NLIW packets in different images from the same source region at the same or at successive tidal cycles.

As NLIWs propagate over the continental shelf with varying depth, NLIWs will continually change their propagating velocity and their shape. It is not practical to monitor the propagation of NLIWs over the continental shelf by deploying costly moorings at many fixed locations, or by tracing NLIWs with research vessels. Usually, numerical models are used to relate NLIW-like disturbances that are found at two moorings that are tens of kilometres apart. Simulation requires assigning initial states, such as the amplitude of the NLIW, the thickness and density structure for the simplest two-layer case. If we do not have an in situ measurement of the layer thickness, the amplitude of the NLIW or the propagation velocity, we can estimate the propagation speed of the linear internal wave (LIW) from hydrological data, and then estimate the NLIW propagation speed from the distance of the bright band and the dark band in SAR or MODIS images, based on the soliton theory of Kortewegde Vries (KdV; Liu et al. 2004).

\section{Method}

The propagation of an NLIW can be estimated from the propagation of an LIW, which depends on the frequency of the internal wave and the stratification of the water density. Historical conductivity-temperature-depth (CTD) data are used because there were no in situ data at the time that the satellite images were acquired. Because of uneven distribution of the CTD casts (figure 3 ) over uneven distribution of bathymetry in the spatial domain, bilinear regression is used to interpolate the CTD data into data-void regions:

$$
p=a x+b y+c x y+d
$$

where $p$ is the temperature, $x$ is the longitude, $y$ is the latitude, and $a, b, c$ and $d$ are regression coefficients.

The temperature and density $(\rho)$ over a latitude-longitude grid were then derived with the above regression method. Since salinity $S(x, y, z, t)$ may be influenced by precipitation on a small scale, only the horizontally averaged salinity profile $S(z)$ is used in the computation of $\rho$. In a region of $300 \mathrm{~m}$ depth, the estimated phase velocity of the mode 1 internal wave changes from $1.41 \mathrm{~m} \mathrm{~s}^{-1}$ using $S(z)$ to $1.42 \mathrm{~m} \mathrm{~s}^{-1}$ using local salinity $S(x, y, z, t)$.

Under the assumption of a linear, hydrostatic, frictionless and Boussinesq approximation, the characteristic equation for the vertical velocity $\varphi$ (Gill 1982) of an LIW can be derived: 


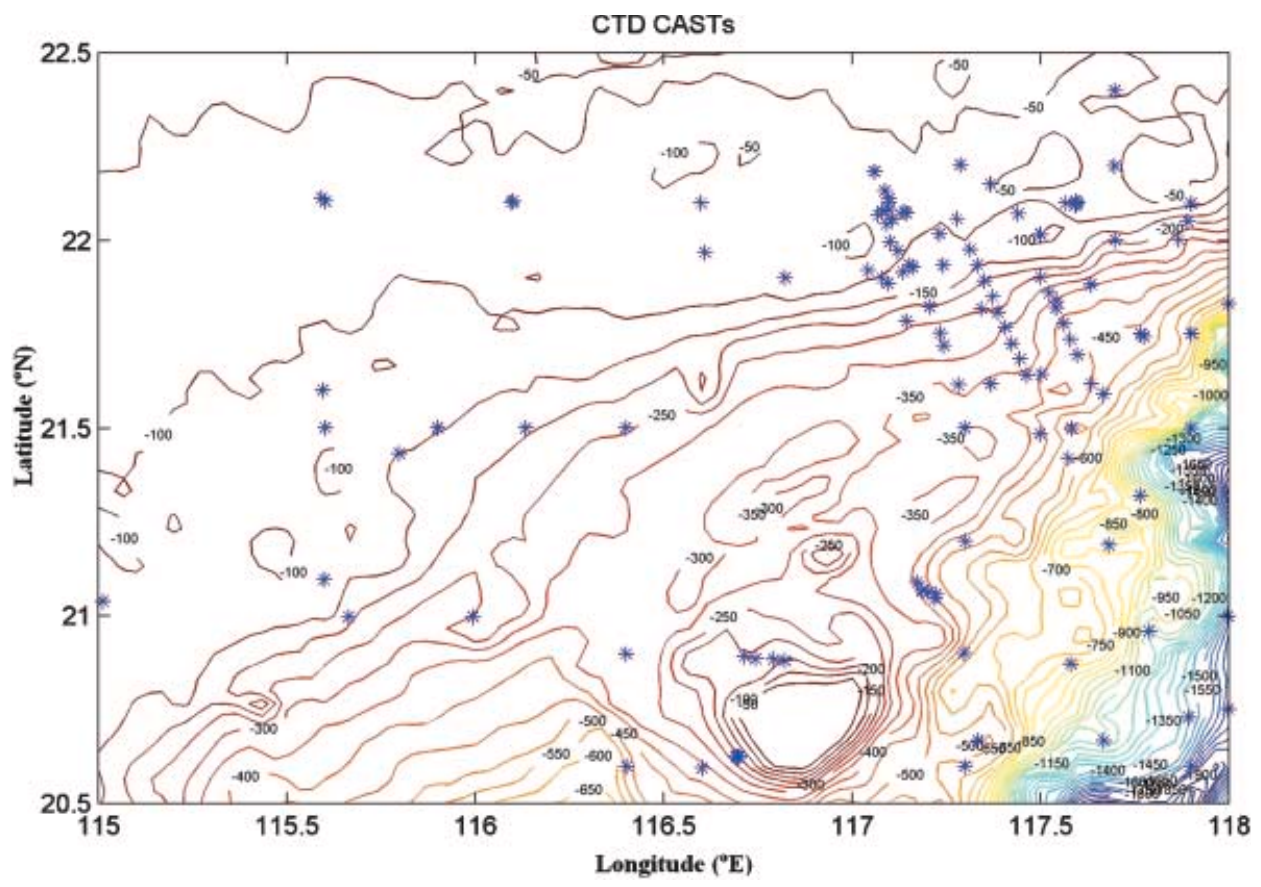

Figure 3. Distribution of archived CTD casts in April and May (source: National Centre of Ocean Research, National Taiwan University).

$$
\begin{gathered}
\frac{\mathrm{d}^{2} \varphi_{j}}{\mathrm{~d} z^{2}}+\varphi_{j}\left[N^{2}(z)-\omega^{2}\right] \lambda_{j}^{2}=0 \\
\lambda_{j}^{2}=\frac{k^{2}}{\omega^{2}-f^{2}} \\
k^{2}=\lambda_{j}^{2} \times\left(\omega^{2}-f^{2}\right)
\end{gathered}
$$

where $\lambda$ is the eigenvalue, $k$ the wavenumber, $\omega$ the angular frequency of the tidal constituents, $f$ the Coriolis parameter, and $N(z)$ the Brunt-Väisälä frequency given by:

$$
N^{2}(z)=-\frac{g}{\rho} \frac{\mathrm{d} \rho}{\mathrm{d} z}
$$

The boundary condition for the governing equation of LIW is $\varphi_{j}(0)=\varphi_{j}(-H)=0$, and normalization is $\varphi_{\max }=1$.

Let $C_{j}$ represent the phase speed of the $j$ th baroclinic mode. Since the NLIW in the SCS is dominated by the first baroclinic mode, we consider only $C_{1}$. The coefficients of the KdV equation are (Liu et al. 2004):

$$
\alpha=\frac{3 C_{1} \int_{-H}^{0} \frac{\mathrm{d}^{3} \varphi}{\mathrm{d} z^{3}} \mathrm{~d} z}{2 \int_{-H}^{0} \frac{\mathrm{d}^{2} \varphi}{\mathrm{d} z^{2}} \mathrm{~d} z}
$$




$$
\gamma=\frac{\int_{-H}^{0} \varphi^{2} \mathrm{~d} z}{2 \int_{-H}^{0} \frac{\mathrm{d}^{2} \varphi}{\mathrm{d} z^{2}}}
$$

NLIWs have balances among nonlinear, dispersive and dissipative processes. The $\mathrm{KdV}$ equation for describing the propagation of a soliton is a good approximation for a steady-state weakly propagating NLIW (Grue et al. 1999). The equation and solution of $\mathrm{KdV}$ for the non-linear first mode are (Liu et al. 2004):

$$
\begin{gathered}
A_{t}+C_{1} A_{x}+\alpha A A_{x}+\gamma C_{1} A_{x x x}=0 \\
A(x, t)=A_{0} \operatorname{sech}^{2}\left(\frac{x-C_{n} t}{L}\right)
\end{gathered}
$$

where $A_{0}$ is the amplitude of the NLIW that propagates at speed $C_{n}, C_{1}$ is the propagation speed of the first mode LIW, $\alpha$ is the coefficient of the nonlinear term, $\gamma$ is the coefficient of the dispersion term, $A_{t}$ and $A_{x}$ are partial differentials of $A$ with respect to $t$ and $x$, respectively, and $L$ is the NLIW half-width.

The NLIW amplitude, half-width and phase speed $C_{n}$ can be derived from the following equations (Liu 1988):

$$
\begin{gathered}
A_{0}=\frac{12 \gamma}{\alpha L^{2}} \\
C_{n}=C_{1}+\frac{\alpha A_{0}}{3}
\end{gathered}
$$

The propagation velocity $C_{n}$ of an NLIW (Osborne and Burch 1980, Liu et al. 1985, 2004, Ramp et al. 2004) can be computed from in situ observation of the isotherm displacement, the NLIW amplitude $A_{0}$. However, satellite images only show the surface signatures of NLIWs, such as the change in surface roughness due to NLIWs. Since the short surface gravity wave travels slower than NLIWs, and NLIWs have nonuniform horizontal orbital velocity, surface waves will be converged and diverged by the passing NLIWs, and result in changes in surface roughness (Hsu and Liu 2000). Therefore, satellite images of SAR and MODIS show patterns that are related to surface roughness caused by the NLIW.

As the horizontal velocity associated with an NLIW has a fixed relationship with the displacement of isotherms, there is mathematical relationship between the half-width $L$ and the distance between maximal convergence and maximal divergence $D$ :

$$
L=D / 1.32
$$

The maximal convergence and maximal divergence are the brightest band and the darkest band, respectively, in SAR images. Therefore, $L$ can be estimated from satellite images (Hajji et al. 1999, Small et al. 1999, Zhang et al. 2001, Liu et al. 2004) by measuring $D$, the distance between the brightest band and the darkest band. Satellite images as shown in figure 2 are used to derive $L$ using equation(12). This rule of thumb may be the opposite for optical images of MODIS.

There is an underlying assumption in equation (12) that the short gravity wave is generated by surface wind of uniform speed and direction, such that the change in 
surface roughness as viewed by SAR is only due to the nonuniform horizontal current.

As the NLIW propagates, its shape also evolves with internal processes such as breaking, disintegration, dissipation and modal decomposition, and with external environmental parameters such as particular changes in stratification, current and bathymetry. Two $D$ s are derived from NLIW patterns of two successive satellite images, and linear interpolation of $D$ between these two fronts is taken as the firstorder approximation of $D$ of the NLIW evolutes on the continental shelf. That is, $L$ is assumed to change linearly from $118^{\circ} \mathrm{E}$ to $116^{\circ} \mathrm{E}$.

From the above method, we can obtain get $D$ from satellite images (figure 2 ) and derive $L$ from equation (12). We assumed that $L$ changes linearly from $118^{\circ} \mathrm{E}$ to $116^{\circ} \mathrm{E}$ and the values of $L$ at $118^{\circ} \mathrm{E}$ and $116^{\circ} \mathrm{E}$ are $1132 \mathrm{~m}$ and $795 \mathrm{~m}$, respectively. According to KdV theory, equations (10) and (11), we can compute the phase speed $C_{n}$ of the NLIW over the region of study, and contour the isolines of $C_{n}$, as in figure 4.

When an NLIW propagates through the region northeast of Dongsha Atoll $\left(116.8^{\circ} \mathrm{E}, 20.7^{\circ} \mathrm{N}\right)$, it will pass through regions of different $C_{n}$ and be refracted according to Snell's law:

$$
\sin \theta^{\mathrm{ref}} / \sin \theta^{\text {in }}=C^{\mathrm{ref}} / C^{\text {in }}
$$

where $\theta^{\text {ref }}$ is the angle of refraction, $\theta^{\text {in }}$ is the angle of incidence (i.e. the angle between contours of constant $C_{n}$ and NLIW fronts), $C^{\text {ref }}$ is the velocity of the

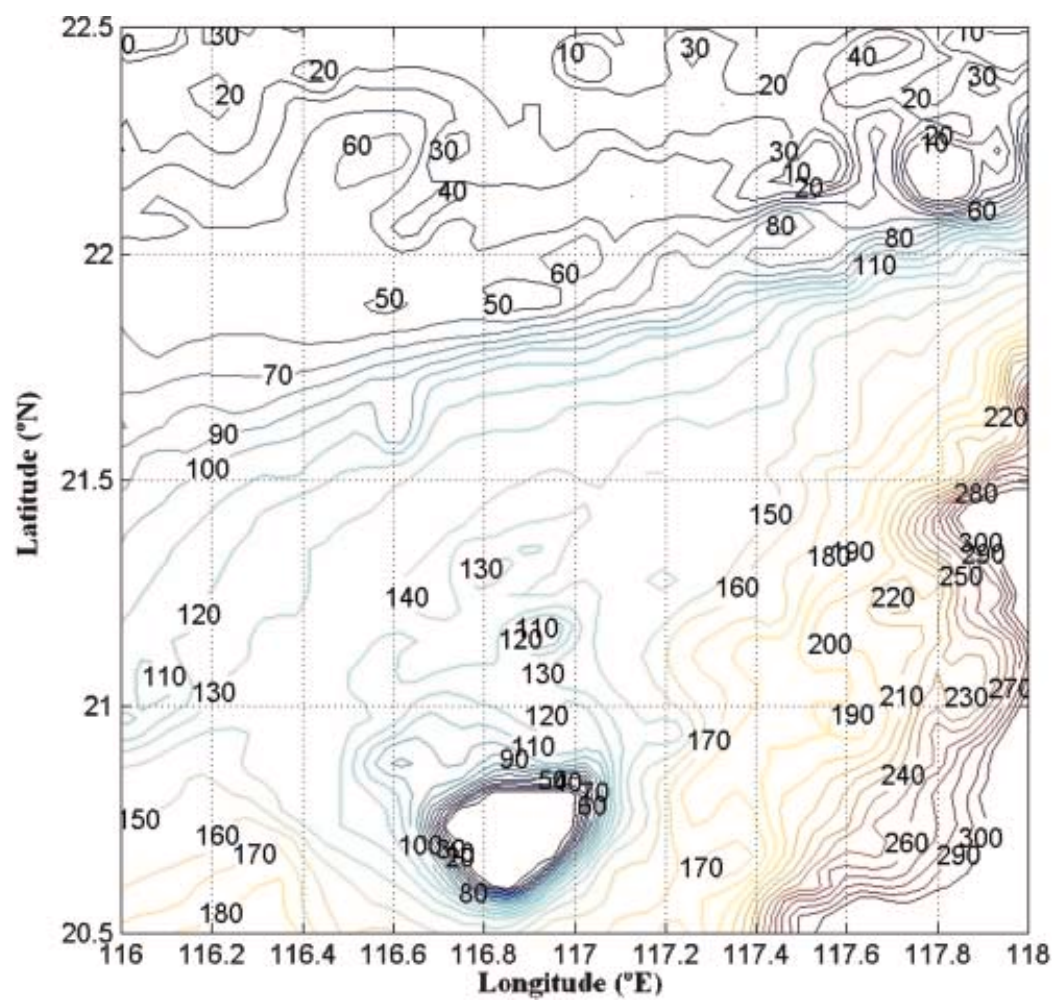

Figure 4. Contour of nonlinear internal wave (NLIW) phase speed $C_{n}\left(\mathrm{~m} \mathrm{~s}^{-1}\right)$. 
refracted wave, and $C^{\text {in }}$ is the velocity of the incident wave. Besides the refraction, waves will also be carried by ocean currents, including tidal current, eddies, etc. These factors are not included in the analysis because they are much smaller than the propagation speed of the NLIW, the tidal effect is averaged out in one tidal cycle, and there is no in situ observation of velocity data.

\section{Results}

Satellite images of features over land are pictures of non-moving targets. After registering every pixel by latitude and longitude, the features can be easily identified. Oceanic features are mostly dynamic features: moving or short-lived. Theoretical prediction is needed to relate oceanic features in one image, in two images at different times, or even in two images at different times and taken by different satellite sensors

The first application of the NLIW path prediction is to sieve out pairs of NLIW packets in one image. In a MODIS image (figure 2), there are many packets of NLIWs, with two very large packets at $117.7^{\circ} \mathrm{E}$ and $116.5^{\circ} \mathrm{E}$. These two packets may be generated at the continental shelf break, at the Hengchun submarine ridge between Taiwan and Luzon Islands, or at the sills between Batan Islands. Aside from where they were generated, the question is: are they related? That is, were they generated at the same region but at different tidal cycles?

If two packets of NLIWs were generated at the same source region, then their separation is the distance of successive NLIWs. Ramp et al. (2004) asserted that the larger group (type A) of NLIWs from Luzon Strait had a period of occurrence of about $24 \mathrm{~h}$. Figure 5 is a plot of the NLIW frontal locations in figure 2, added with

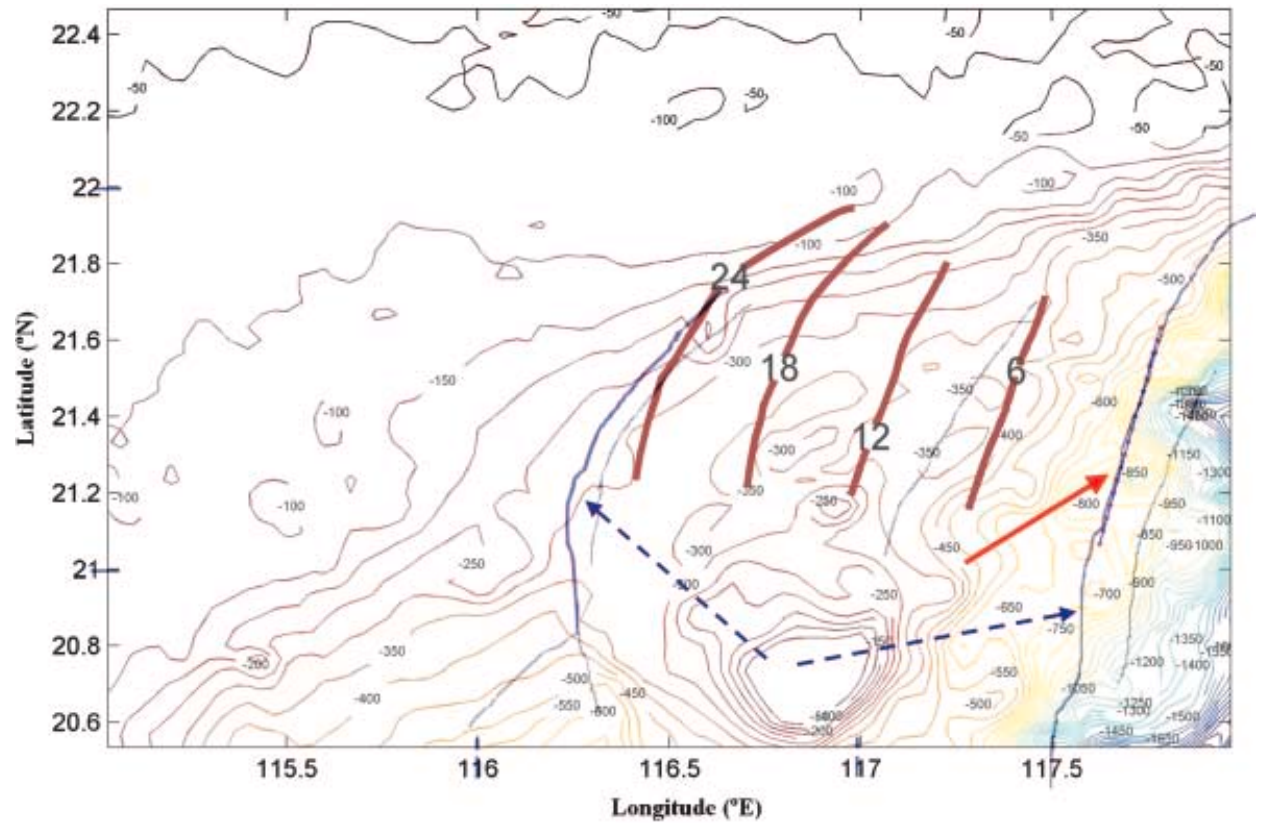

Figure 5. Comparison of NLIW front location (thin blue lines) in the 7 May 2003 Terra MODIS image of Channel 2 vs. those predicted (thick brown lines) from the initial location (red arrow); we can sieve out pairs of NLIWs (broken blue lines) from the same source region but $24 \mathrm{~h}$ apart. 
predicted frontal locations of NLIW fronts after 6, 12, 18 and $24 \mathrm{~h}$ from $117.7^{\circ} \mathrm{E}$. With this prediction, we can easily sieve out pairs of NLIWs from the same source region (Luzon Strait), but $24 \mathrm{~h}$ apart. Other packets of NLIW fronts in the image may be generated at other places, at other times or by other mechanisms; for example, the middle front is probably an NLIW of type B that has a single line and less contrast (figure 2) than the NLIW fronts near $117.7^{\circ} \mathrm{E}$ (A-wave).

The second application of the NLIW path prediction is to pair NLIW packets in different satellite images of the same day. For example, the NLIW on 1 May 2005 is derived from the Aqua MODIS image at 05:10 (figure 6(a)) and is compared with the Envisat ASAR image at 14:13 (figure 6(b)), to verify the prediction of the NLIW propagation path (figure $6(c)$ ).

To determine whether two groups of NLIW fronts in two different types of satellite images that were taken at different times are of the same group of NLIW fronts, the path prediction process is applied. Group A of NLIW is visible on the Aqua MODIS image at $05: 10$ on 1 May 2005 in figure 6(a), Group B is on the Envisat ASAR image at 14:13 on 1 May 2005 in figure 6(b). These two images are taken about $9 \mathrm{~h}$ apart. Figure 6(c) compares the location of Group B (blue lines) vs. Group A, which is propagated from the location of the green lines to the thick brown lines at the time of the SAR images. After $9 \mathrm{~h}$, the predicted location of the leading green NLIW coincides with the observed leading blue NLIW. This prediction demonstrates the reliability of path prediction on NLIW, and its usefulness in linking different satellite images.

Another useful application of predicting NLIW location is for confirmation of a faint signal by locating its successor at the next tidal cycle. One example is the image (figure 7) of the Terra MODIS Channel 2 on 20 May 2003, where a clear pair of NLIW fronts (NLIW type A) $24 \mathrm{~h}$ apart are indicated with dotted arrows. NLIW fronts are visible by the satellite only if the NLIW amplitude is large and the surface wind is in the correct range. Wind and ocean currents can also produce sea surface patterns in satellite images. Interpretation of satellite images is difficult when the surface signature of the NLIW fades away, when its amplitude decreases with propagation on the shelf. If a roughness pattern has a similar shape to the NLIW and is at the predicted location (blue box in figure 7) to nearby NLIWs (indicated by the solid red arrow) with a clear signature, then we can accept this faint pattern as an NLIW with confidence. If no NLIW pattern at the 'upstream' side with one period apart is found, then other evidence is needed before accepting it as an NLIWgenerated surface roughness pattern. Two groups of NLIWs are indicated in figure 7: two packets of A-waves $24 \mathrm{~h}$ apart (dotted arrows), and two packets of B-waves $24.8 \mathrm{~h}$ apart (red arrow and the faint signature in the blue box).

\section{Conclusions}

There is as yet no unified theory for explaining all NLIWs in the SCS. In this study we used historical CTD data to derive the first mode of the LIW, and then used the $\mathrm{KdV}$ equation of weakly propagating NLIWs to predict the propagation path and the location of the NLIWs over the continental shelf of the northern SCS. The basic assumptions include a negligible effect from the mean current and tidal current, and also from higher order nonlinearity, and that the half-width of the NLIW changes linearly between two fronts that are no more than $24 \mathrm{~h}$ apart. For the 11 cases in table 1 , the distance-weighted bias and standard deviation are $-1 \%$ and $4.4 \%$, respectively, in the predicted propagation path and the propagation speed. 

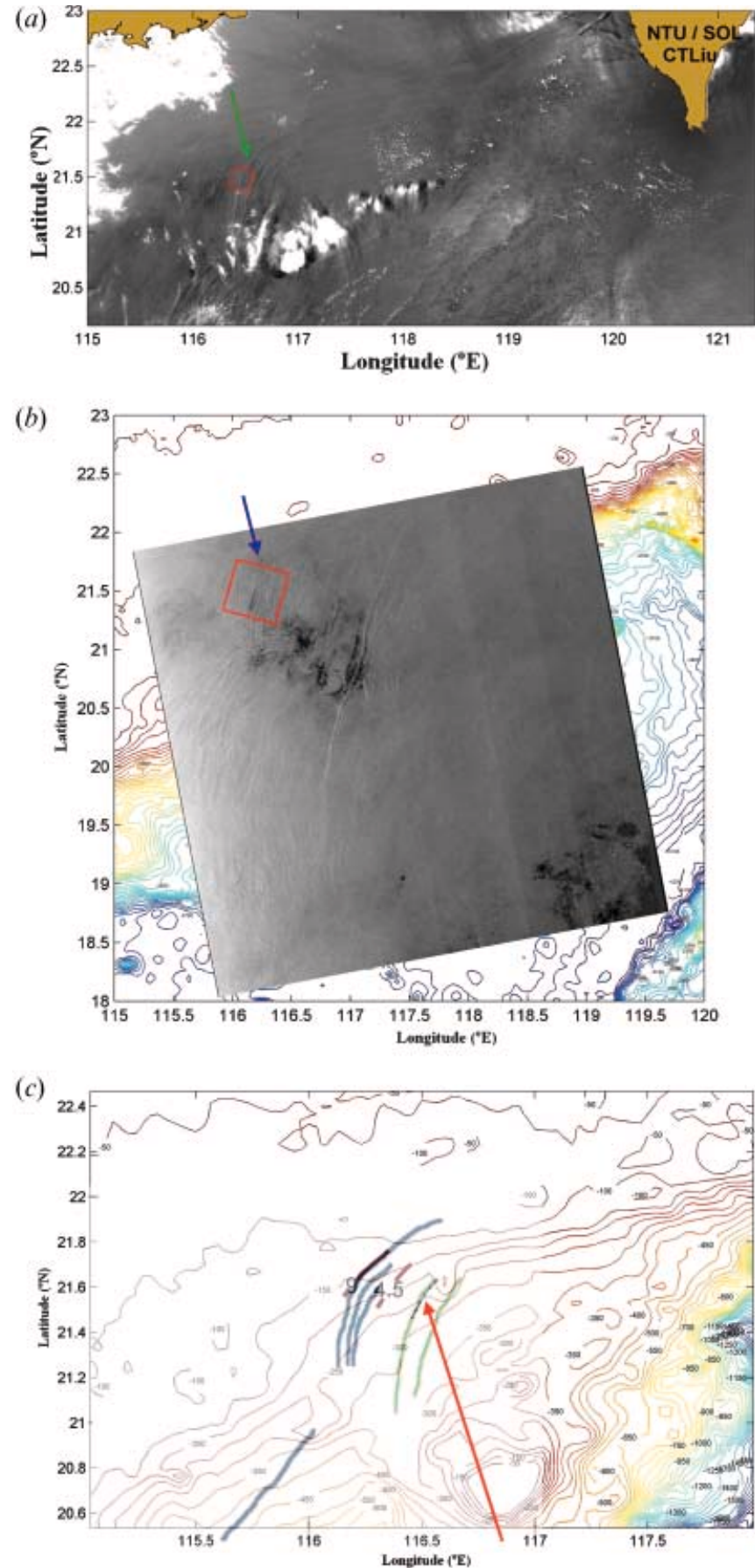

Figure 6. (a) Aqua MODIS image at 05:10 on 1 May 2005 (courtesy of NASA); (b) Envisat ASAR image at 14:13 on 1 May 2005 (courtesy of ESA); $(c)$ comparison of NLIW front location (blue lines) in the ASAR image of 14:13 on 1 May 2005 vs. those predicted (thick brown lines) from the initial location (red arrow and green line) in MODIS image 1 May 2005 satellite image. This prediction demonstrates the reliability of path prediction on NLIW, and its usefulness in linking different satellite images. 


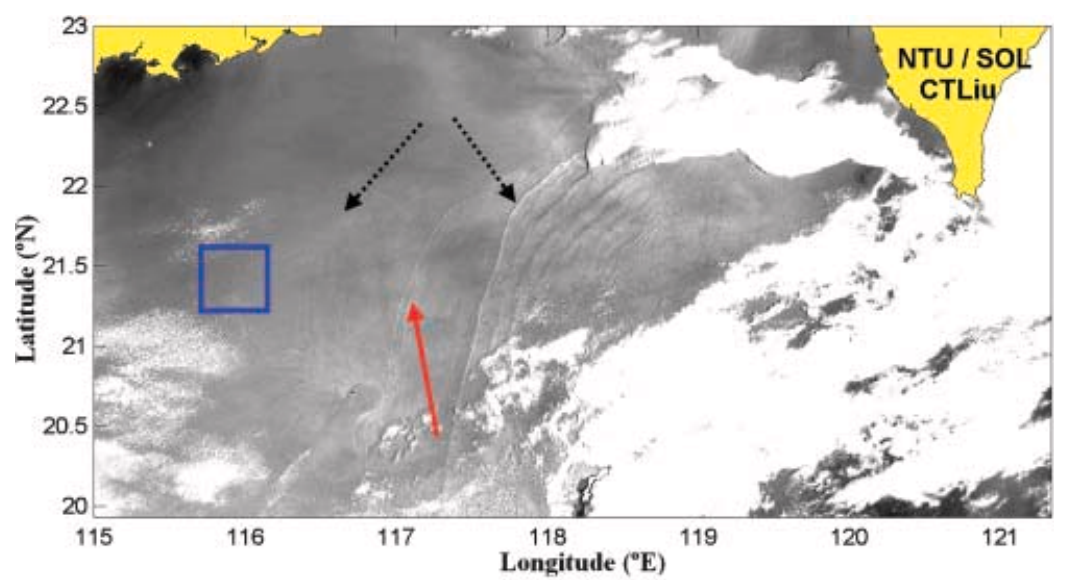

Figure 7. Confirming the faint signal by locating its successor at the next period. In this image of the Terra MODIS Channel 2 on 20 May 2003, a clear pair of NLIW fronts (A-waves) that are $24 \mathrm{~h}$ apart are indicated by dotted arrows. The faint NLIW signature in the square is confirmed by the NLIW front (solid arrow, B-wave), which is of the same origin but $24.8 \mathrm{~h}$ apart.

Ramp et al. (2004) plotted the predicted NLIW phase speed from various NLIW models against observation at water depth $320 \mathrm{~m}$. From that figure, $C_{n}=1.5 \mathrm{~m} \mathrm{~s}^{-1}$ was predicted by stratified $\mathrm{KdV}$, while the observed values are $C_{n} \approx 1.5,1.43,1.37$ and $1.17 \mathrm{~m} \mathrm{~s}^{-1}$. Their root mean square difference from the $\mathrm{KdV}$-predicted $1.5 \mathrm{~m} \mathrm{~s}^{-1}$ is $0.18 \mathrm{~m} \mathrm{~s}^{-1}$, or $12 \%$ of $1.5 \mathrm{~m} \mathrm{~s}^{-1}$.

If the internal waves that were observed by Ramp et al. (2004) contain both LIWs and NLIWs, then we should compare them separately. Under this assumption, the $\mathrm{KdV}$ equation can explain the NLIW propagation equally well for the in situ

Table 1. Statistics for the accuracy in comparing the predicted location of nonlinear internal waves vs. those observed in the same satellite image (cases 1-7), or in another satellite image (cases 8-11) of nearest time. Fronts of higher contrasts are categorized as A-wave in Ramp et al. (2004).

\begin{tabular}{|c|c|c|c|c|c|c|c|c|}
\hline Case & Satellite & System & Date & UTC & $\begin{array}{l}\text { A/B } \\
\text { type }\end{array}$ & $\begin{array}{c}\text { Starting } \\
\text { longitude } \\
\left({ }^{\circ} \mathrm{E}\right)\end{array}$ & $\begin{array}{l}\text { Predicted } \\
\text { propagation } \\
(\mathrm{km})\end{array}$ & $\begin{array}{c}\text { Error } \\
(\%)\end{array}$ \\
\hline 1 & Terra & MODIS & 7 May 2003 & $03: 25$ & A & 117.8 & 133 & -4.7 \\
\hline 2 & Terra & MODIS & 18 April 2004 & $02: 55$ & A & 117.8 & 126 & -2.4 \\
\hline 3 & Terra & MODIS & 20 May 2003 & $02: 55$ & A & 117.7 & 126 & -5.3 \\
\hline 4 & Aqua & MODIS & 29 April 2005 & $05: 25$ & A & 117.5 & 112 & 4.8 \\
\hline 5 & Terra & MODIS & 30 April 2005 & 03:00 & A & 117.8 & 129 & -2 \\
\hline 6 & Radarsat & SAR & 7 May 2005 & $10: 18$ & A & 117.3 & 104 & 1.3 \\
\hline 7 & Terra & MODIS & 20 May 2003 & $02: 55$ & B & 117.1 & 105 & 1.2 \\
\hline \multirow[t]{2}{*}{8} & Aqua & MODIS & 1 May 2005 & $05: 10$ & A & 116.5 & 32 & 4.3 \\
\hline & Envisat & MODIS & 1 May 2005 & $14: 13$ & & & & \\
\hline \multirow[t]{2}{*}{9} & Aqua & MODIS & 29 April 2005 & $05: 25$ & A & 117.6 & 106 & 1.9 \\
\hline & Terra & MODIS & 30 April 2005 & 03:00 & & & & \\
\hline \multirow[t]{2}{*}{10} & Terra & MODIS & 30 April 2005 & 03:00 & A & 117.8 & 134 & 1.4 \\
\hline & Aqua & MODIS & 1 May 2005 & $05: 10$ & & & & \\
\hline \multirow[t]{2}{*}{11} & Aqua & MODIS & 17 May 2005 & $05: 10$ & A & 116.5 & 40 & -16 \\
\hline & Envisat & ASAR & 17 May 2005 & $14: 10$ & & & & \\
\hline
\end{tabular}


observation (Ramp et al. 2004) and for our satellite images, and there are LIWs that were not observed in our SAR images, nor in our MODIS images.

In this study, no concurrent in situ measurement was available, the prediction on the path and phase speed of NLIW depends totally on historical CTD data and satellite images. The results are comparable or better than those from mooring data. This means that this method should be applicable to predicting NLIWs over other continental shelves with reasonable accuracy.

This method has been used to estimate the location of an NLIW as it propagates, and can be used to distinguish NLIW packets of different origins, that is to sieve out NLIW packets that were generated at the same place (sill, shelf break, etc.). It can also be used to relate the NLIWs in different satellite images and the observed disturbance of temperature and water velocity from fixed moorings.

\section{Acknowledgements}

We are grateful to Chang-Wei Lee (NTU) for providing the MODIS data. We also thanks the European Space Agency (ESA) for the Envisat ASAR image, and NASA for the MODIS images. This study was co-sponsored by the ROC National Science Council and the U.S. Office of Naval Research.

\section{References}

Bole, J.B., Ebbesmeyer, C.C. and Romea, R.D., 1994, Soliton currents in the South China Sea: measurement and theoretical modeling. In 1994 Offshore Technology Conference, Houston, Texas, 2-5 May 1994, Paper OTC 7417, pp. 367-376.

Fett, R. and Rabe, K., 1977, Satellite observation of internal wave refraction in the South China Sea. Geophysical Research Letters, 4, pp. 189-191.

Gill, A.E., 1982, Atmosphere-Ocean Dynamics (San Diego: Academic Press).

Grue, J., Jensen, A., Rusas, P.O. and Sveen, J.K., 1999, Properties of large-amplitude internal waves. Journal of Fluid Mechanics, 38, pp. 257-278.

Haju, H., Sole, S. and Ramamonjiarisoa, A., 2000, Analysis and prediction of internal waves using SAR image and non-linear model. SAR Workshop: CEOS Committee on Earth Observation Satellites; Working Group on Calibration and Validation, 26-29 October 1999, Toulouse, France. Robert A. Harris and L. Ouwehand (Eds.), ESA-SP, 40, p. 513 (Paris: European Space Agency).

Hsu, M.K. and Liu, A.K., 2000, Nonlinear internal waves in the South China Sea. Canadian Journal of Remote Sensing, 26, pp. 72-81.

Hsu, M.K., Liu, A.K. and Liu, C., 2000, A study of internal waves in the China Seas and Yellow Sea using SAR. Continental Shelf Research, 20, pp. 389-410.

LiU, A.K., 1988, Analysis of nonlinear internal waves in the New York Bight. Journal of Geophysical Research, 93, pp. 12317-12329.

Liu, A.K., Apel, J.R. and Holbrook, J.R., 1985, Nonlinear internal wave evolution in the Sulu Sea. Journal of Physical Oceanography, 15, pp. 1613-1624.

Liu, A.K., Chang, Y.S., Hsu, M.K. and Liang, N.K., 1998, Evolution of nonlinear internal waves in the East and South China Seas. Journal of Geophysical Research, 103, pp. 7995-8008.

LiU, A.K. and Hsu, M.K., 2004, Internal wave study in the South China Sea using synthetic aperture radar (SAR). International Journal of Remote Sensing, 25, pp. 1261-1264.

Liu, A.K., RAmP, S.R., Zhao, Y. and TANG, T.Y., 2004, A case study of internal solitary wave propagation during ASIAEX 2001. IEEE Journal of Oceanic Engineering, 29, pp. $1144-1156$.

Liu, C.-T., Pinkel, R., Hsu, M.-K., Klymak, J., Chen, H.-W. and Villanoy, C., 2006, Non-linear internal waves from the Luzon Strait. Eos, Transactions, American Geophysical Union, 87, pp. 449-451. 
Osborne, A.R. and Burch, T.L., 1980, Internal solitons in the Andaman Sea. Science, 208, pp. $451-460$.

Ramp, S.R., TAng, T.Y., Duda, T.F. and Lynch, J.F., 2004, Internal solitons in the northeastern South China Sea. IEEE Journal of Oceanic Engineering, 29, pp. 1157-1181.

Small, J., Hallock, Z., Pavey, G. and Scott, J.C., 1999, Observations of large amplitude internal waves at the Malin Shelf edge during SESAME 1995. Continental Shelf Research, 19, pp. 1389-1436.

Zhao, Z., Klemas, V., Zheng, Q. and Yan, X.H., 2004, Remote sensing evidence for baroclinic tide origin of the internal solitary waves in the northern South China Sea. Geophysical Research Letters, 31, pp. L06302.

Zheng, Q., Yuan, Y., Klemas, V. and Yan, X.H., 2001, Theoretical expression for an ocean internal soliton synthetic aperture radar image and determination of the soliton characteristic half width. Journal of Geophysical Research, 106, pp. 31415-31423. 